\title{
Development and usability testing of a Web-based decision aid for families of patients receiving prolonged mechanical ventilation
}

Christopher E Cox ${ }^{1,2^{*}}$, Nicholas G Wysham ${ }^{1,2,3}$, Brenda Walton ${ }^{1,2}$, Derek Jones ${ }^{1,2}$, Brian Cass ${ }^{4}$, Maria Tobin ${ }^{4}$, Mattias Jonsson ${ }^{5}$, Jeremy M Kahn ${ }^{6}$, Douglas B White, ${ }^{6}$ Catherine L Hough ${ }^{7}$, Carmen L Lewis ${ }^{8}$ and Shannon S Carson ${ }^{9}$

\begin{abstract}
Background: Web-based decision aids are increasingly important in medical research and clinical care. However, few have been studied in an intensive care unit setting. The objectives of this study were to develop a Web-based decision aid for family members of patients receiving prolonged mechanical ventilation and to evaluate its usability and acceptability.
\end{abstract}

Methods: Using an iterative process involving 48 critical illness survivors, family surrogate decision makers, and intensivists, we developed a Web-based decision aid addressing goals of care preferences for surrogate decision makers of patients with prolonged mechanical ventilation that could be either administered by study staff or completed independently by family members (Development Phase). After piloting the decision aid among 13 surrogate decision makers and seven intensivists, we assessed the decision aid's usability in the Evaluation Phase among a cohort of 30 surrogate decision makers using the Systems Usability Scale (SUS). Acceptability was assessed using measures of satisfaction and preference for electronic Collaborative Decision Support (eCODES) versus the original printed decision aid.

Results: The final decision aid, termed 'electronic Collaborative Decision Support', provides a framework for shared decision making, elicits relevant values and preferences, incorporates clinical data to personalize prognostic estimates generated from the ProVent prediction model, generates a printable document summarizing the user's interaction with the decision aid, and can digitally archive each user session. Usability was excellent (mean SUS, $80 \pm 10$ ) overall, but lower among those 56 years and older (73 \pm 7 ) versus those who were younger ( $84 \pm 9$ ); $p=0.03$. A total of $93 \%$ of users reported a preference for electronic versus printed versions.

Conclusions: The Web-based decision aid for ICU surrogate decision makers can facilitate highly individualized information sharing with excellent usability and acceptability. Decision aids that employ an electronic format such as eCODES represent a strategy that could enhance patient-clinician collaboration and decision making quality in intensive care.

Keywords: Critical illness; Usability; Patient reported outcomes; Patient-centeredness; Surrogate decision making; Decision aid; Decision support; Chronic critical illness; Prolonged mechanical ventilation

\footnotetext{
* Correspondence: christopher.cox@duke.edu

${ }^{1}$ Department of Medicine, Division of Pulmonary and Critical Care Medicine,

Duke University, Durham, NC 27710, USA

${ }^{2}$ Program to Support People and Enhance Recovery, Duke University,

Durham, NC, USA

Full list of author information is available at the end of the article
} 


\section{Background}

Decision making in the setting of critical illness can be difficult for patients, families, and clinicians alike [1]. When such decision making is not collaborative or is perceived to be inadequate, the patient centeredness of care suffers and the decision makers themselves may experience subsequent psychological distress [2]. Shared decision making, a dynamic process of consensus building where responsibility for making decisions reflecting the alignment of values and choice is shared between health care team and the patient or patient's surrogate, is a strategy increasingly utilized to address these problems $[3,4]$. Although shared decision making is the recommended strategy for navigating choices in complex treatment plans $[4,5]$, evidence suggests that it remains insufficiently adopted [6].

Decision aids are printed, electronic, or video programs that can promote shared decision making and improve decision making quality [7]. We recently developed a printed decision aid to assist the process of shared decision making among surrogate decision makers of critically ill patients and their providers facing a decision about the provision of prolonged life support [8]. This decision aid showed evidence of feasibility and acceptability, while also demonstrating plausible impact on reducing surrogateclinician discordance about prognosis, psychological distress, and decisional conflict. However, printed decision aids have a number of limitations. They cannot be easily individualized, they are not interactive, require cumbersome manual data entry after completion, and they may be perceived as less engaging than other formats.

To address these problems, we sought to expand a brief printed prolonged mechanical ventilation decision aid to a fully electronic, multi-function version that we termed 'electronic Collaborative Decision Support' (eCODES). We studied whether or not eCODES was actually usable and acceptable by decision makers for use in clinical care and research. Here, we report the results of this effort as well as the lessons we learned during the developmental process that could assist others engaging in similar future projects.

\section{Methods}

This study includes two components, a Development Phase and an Evaluation Phase (Figure 1), completed over a period of nearly 3 years. In the Development Phase, we adapted our previously validated printed prolonged mechanical ventilation decision aid to create a Web-based version (eCODES). Family members who piloted eCODES provided written informed consent. In the Evaluation Phase, we measured eCODES' usability, acceptability, and feasibility among family members of ICU patients. We conducted this phase under a waiver of consent granted by the Duke University Institutional Review Board because we did not record any personal information, only gender and age range. The timeline of the entire decision aid project including both the printed and Web-based versions is shown in Additional file 1: Figure S1 ("Evolution and development of web-based decision aid).

\section{Phase 1: Development of eCODES Original printed decision aid}

The original prolonged mechanical ventilation decision aid for surrogate decision makers was developed in accordance with the consensus guidelines and piloted in 2009 to 2011 as previously described [8,9]. In short, we developed a brief printed decision aid that framed the

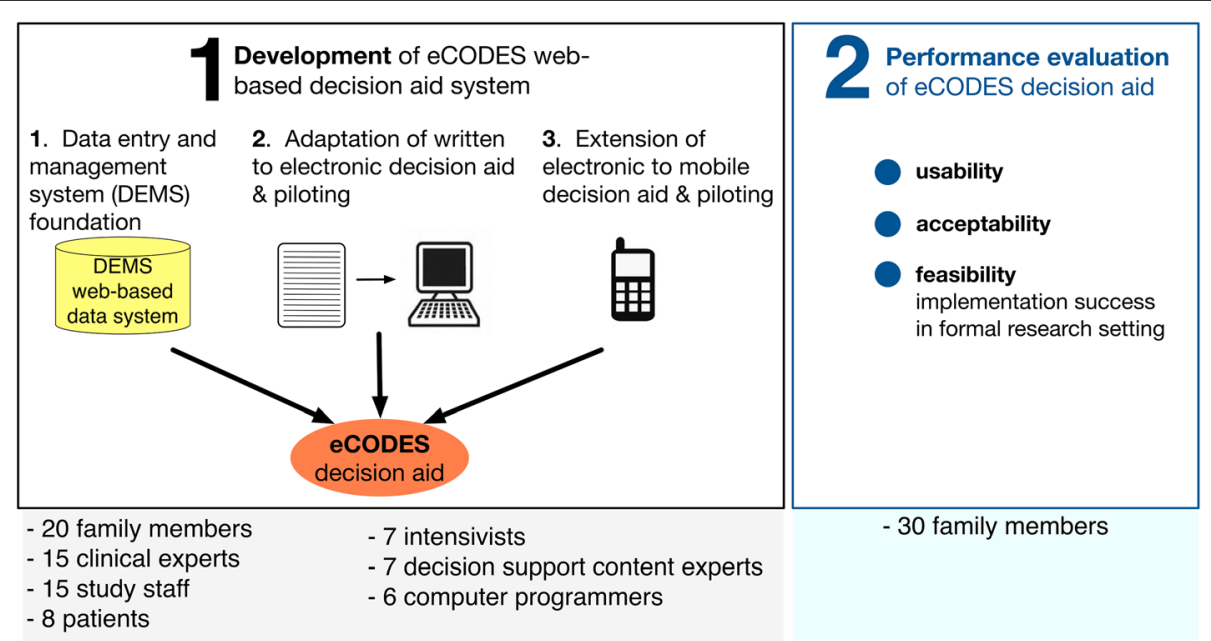

Figure 1 Overview of study. The development of eCODES, a Web-based prolonged mechanical ventilation decision aid, included extension of a data entry and management system to include a study staff-directed electronic decision aid adapted from a printed version. Development also included enhancing eCODES with a mobile functionality, allowing users to view it at their convenience in locations outside a hospital setting. The performance evaluation phase included a formal assessment of usability, acceptability, and feasibility. 
decision about prolonged life support preferences as a spectrum ranging from aggressive, survival-focused treatment to care focused purely on symptoms. By helping to place patients along this spectrum, the decision aid provided a concrete framework on which a facilitated discussion between surrogate decision makers and clinicians could take place.

\section{Version 1 of the Web-based decision aid}

The initial Web-based version of the decision aid adapted the printed version nearly page for page, but added a password-protected area that allowed the research team to enter five clinical variables measured on the tenth day of ventilation to populate the day 10 version of the prolonged mechanical ventilation (ProVent) score for prediction of 1-year mortality: age, use of vasopressors, requirement for hemodialysis, platelet count, and trauma status [10]. Our choice to use the ProVent model in the decision aid defined prolonged mechanical ventilation as 10 or more days of ventilation. In this version of the decision aid, prognosis was displayed as a bar graph in early mockups. This version met 11 of the 13 International Patient Decision Aid Standards consensus criteria, two effectiveness criteria are still under evaluation [9].

\section{Version 2 of the Web-based decision aid}

We then worked with a consultant computer programmer and graphic design firm to develop a more engaging version of the decision aid that could be integrated into a secure data management system. We created storyboards, page outlines, computational infrastructure for entry of variables necessary for the ProVent model, and a better graphical display of prognosis. We added more extensive content on the decision itself, about common ICU therapies such as mechanical ventilation, and on how to understand prognostic estimates. The final version was a section-tabbed, interactive program that summarized the user's interactions and responses in a single PDF document that could be printed from the website, free of protected health information (PHI).

\section{Version 3 of the Web-based decision aid (eCODES)}

The programming code for the decision aid v2 served as the foundation for the third and final version of the Webbased decision aid, eCODES. eCODES included an improved help function as well as an optional tutorial on using tablet computers. The display of prognostic data was a major focus of revision in this version. In particular, we programmed a page flow to try to display potentially serious prognostic estimates as sensitively and deliberately as possible. eCODES required users to touch different screen areas corresponding to explanatory text in order to move forward (to avoid 'blind clicking' to a page they were unprepared to see) and to also warn them about the information they were about to view. eCODES was first designed to be administered in person on a tablet computer by either a clinical or research team. Soon thereafter, in response to family requests, we added a secure, passwordprotected, HIPAA-compliant, PHI-free version that could be viewed outside the hospital setting. We integrated eCODES into an equally secure Web-based data entry and management system (see Figure 2 and Additional file 2, "Security standards of study data system used to present eCODES.") built specifically for the randomized clinical trial designed to systematically test the impact of the decision aid (NCT01751061).

\section{Phase 2: Evaluation of eCODES Design and participants}

For eCODES formal user testing, we recruited a convenience sample of 30 family members of ICU patients from the medical ICU waiting room at Duke University in six separate sessions between 2 September 2014 and 12 September 2014. The participants were asked to read a standard clinical scenario, perform an eCODES session, and then complete a short interview.

\section{Clinical scenario and eCODES session}

Each participant received an identical one-page printed document (shown in Additional file 3, "Instructions for usability testing."). It described a hypothetical situation in which their 60-year-old loved one had received 10 days of mechanical ventilation and had just initiated hemodialysis. The document also emphasized that their task was to decide what to do next with life support according to the goals of treatment options specified in the original printed prolonged mechanical ventilation decision aid (treatment with comfort as the main goal, aggressive care with survival as the main goal, or treatment that aimed for survival but without prolonged life support) [8]. After reading the document, each participant viewed a tablet computer-based eCODES session that was pre-programmed to display prognosis mirroring the clinical scenario (approximately 70\% likelihood of death within 1 year). They were not coached further at this point.

\section{Interview and study outcomes measures}

Immediately after finishing the eCODES session, the participants completed a short-printed questionnaire to assess the decision aid's usability and acceptability. Usability describes the quality of a user's experience with software or an information technology, taking into account their own needs, values, abilities, and limitations [11]. We used a well-validated, industry standard to measure usability, the Systems Usability Scale (SUS). The SUS is a 10-item, Likert-scaled (strongly agree, agree, neutral, disagree, and strongly disagree) measure with scores ranging from 0 to 100 [12]. The SUS items address to what extent users 


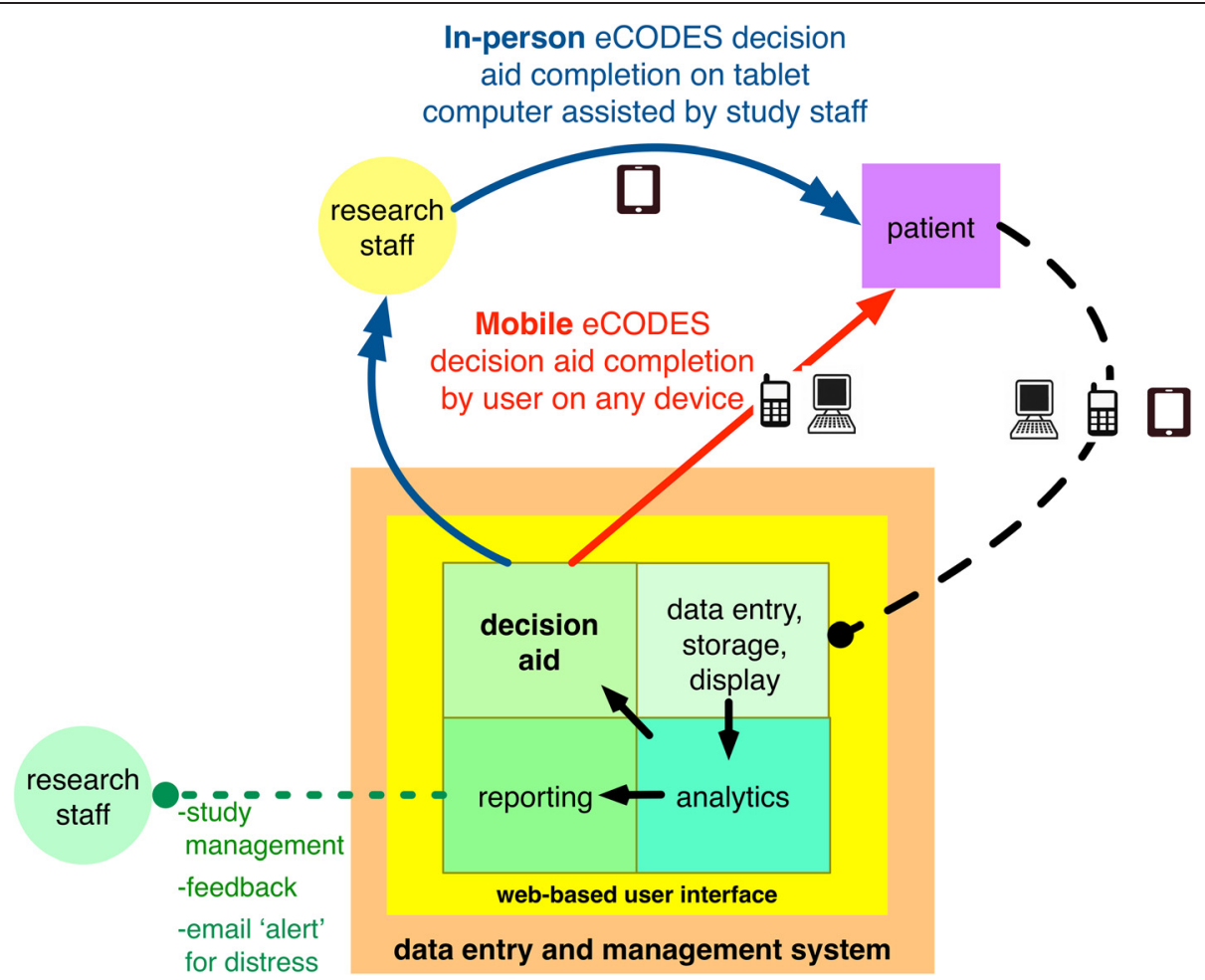

Figure 2 Orientation of eCODES within an electronic data entry and management system. eCODES resides on a secure server and is accessed via a Web user interface. eCODES can be administered by study staff in person or completed securely by surrogate decision makers on a separate device.

perceive the program as complex, cumbersome, easy to use, requiring support of a technical expert to complete, has integrated functions, has consistency, is learned quickly and confidently, or requires significant learning prior to use. The target SUS score was $>70$, representing 'good' usability [13]. Guided by the recommendations of Usability.gov, we also assessed usability domains using Likert-scaled items addressing learnability (how easy it is to accomplish tasks the first time), success rate (login, question completion, viewing all necessary pages), possible barriers, efficiency (task time) [11,14]. We used two sample $t$ tests to compare SUS scores by age range. We assessed acceptability using measures of satisfaction (overall, layout, content, and preference for printed vs. Webbased version) assessed with a 5-point Likert scale; we targeted a satisfaction level of $80 \%$ for 'good' acceptability. The participants provided written open-ended feedback to highlight the eCODES elements they most liked and disliked as additional measures of acceptability. Study staff assessed error rates by comparison of completed eCODES episodes and any translational errors recorded in the study data system. While not the primary aim of this study, we assessed feasibility of eCODES by the rater of successful sessions completed (in person and mobile versions) to date among persons enrolled in the parent randomized controlled trial.

\section{Results}

\section{Phase 1: Development of eCODES Development}

This intensive process of storyboarding, programming, evaluating, and revising across three versions of the decision aid included 20 family members, 15 surrogate decision makers of ICU survivors, 15 clinical research coordinators with extensive experience interviewing patients and families in an ICU research setting, eight ICU survivors who received mechanical ventilation, seven intensivists, seven decision support content experts, and six programmers (Figure 1). In particular, study staff spent many hours testing the decision aid repeatedly as if they were surrogate decision makers, with in-depth examination for potential problems.

The final version of the decision aid, eCODES, included several key characteristics that represented comparative improvements to the printed version. First, it was an engaging, Web-based, graphics-heavy program that could be either administered on a touch screen computer by study staff or viewed on Web-enabled devices outside the hospital setting (see Additional file 4: Figure S2 comparing print to electronic versions). Second, we greatly improved the process by which potentially surprising prognostic information was revealed sensitively for the viewer. We used a combination of techniques to do this which slowed the 
pace of viewing, did not permit 'rapid clicking' through pages by requiring specific screen areas be touched, and asking the user if they were ready to see serious information. Third, the response choices for questions were more intuitively laid out - specifically for items allowing weighting on linear scales (e.g., anchors with 'most' and 'least'). And finally, eCODES included a summary PDF document that was generated at the conclusion of the decision aid session for the purpose of providing a family meeting discussion focus for surrogate decision makers and clinicians.

\section{Piloting eCODES in clinical research settings}

We piloted eCODES in both study staff-administered and self-completed (mobile) versions at Duke University, the University of North Carolina, and the University of Pittsburgh among 13 surrogate decision makers and seven intensivists. Open-ended participant feedback was uniformly satisfactory, and all participants were able to complete the decision aid. Data transfer accuracy between the decision aid and the study data system was hand-verified to be error-free.

\section{Phase 2: Evaluation of eCODES}

A total of 30 participants evaluated the final online decision aid and completed the study interview, 20 of whom (67\%) were female. Twelve surrogates (40\%) were 45 years of age or younger, seven (23\%) were ages 46 to 55 , and 11 (37\%) were 56 years and older. Users generally spent 15 to 20 min completing the decision aid program.

The mean SUS score was $80 \pm 10$ overall, a rating considered to reflect 'excellent' usability [15]. Mean SUS scores were highest among those $<45$ years $(84 \pm 9)$ and lowest among those 66 years of age and older $(67 \pm 8)$ (Table 1$)$. Statistically significant differences in mean SUS score by age were observed between those $\leq 55$ years $(84 \pm 9)$ and those 56 years and older $(73 \pm 7) ; p=0.03$. However, no statistically significant differences were observed within younger participants ( $<45$ vs. 46 to 55$)$ or older participants (56 to 65 vs. 66 and older); $p>0.05$.

While older participants' SUS score was lower than those of younger participants, 10/11 (91\%) of those 56 years and older stated that they would prefer Web-based to printed versions decision aid. Acceptability was further supported by the fact that over $90 \%$ of respondents reported satisfaction with the program overall, its ease of use, its layout, and the instructions. Open-ended written user comments were generally positive as well (Table 2). Representative written responses to the question, 'What did you like most about the program?' included 'easy to use,' 'user-friendly, 'informative,' and 'interactive'. Several respondents' responses suggested that eCODES helped to clarify decisional roles, to focus attention on patients' values, and to show clinicians how family decision makers were leaning in their decision.
Seven (23\%) participants provided written feedback about specific dislikes. Some critiques addressed technical issues such as touch screen capabilities, delays after pressing back/forth buttons, or a general dislike for electronic interfaces. Content critiques were also noted such as by one user who worried that prolonged life support was 'a sensitive topic' while another described eCODES and its sixth grade reading level as 'simplistic'. Suggestions for improvement mapped to the above complaints, asking for improvements in navigation, more illustrations, and more information and detail.

Finally, hand checking of completed decision aid episodes, searchable through our study data entry and management system, showed that all eCODES sessions were complete and produced no data transmission errors. Further, the content of the summary PDFs produced by eCODES was verified to be harmonious with the actual data entered by the participants. To date in our ongoing clinical trial of eCODES [16], all surrogate decision makers have completed the decision aid successfully (215 in person and 37 on either a mobile device or home computer) - observations supporting the feasibility of using eCODES in a research setting.

\section{Discussion}

We developed eCODES, a Web-based decision aid for surrogate decision makers of patients receiving prolonged mechanical ventilation. eCODES was highly usable and acceptable to the target audience based on a standard rating tool. Overall, $93 \%$ of users stated that they preferred eCODES to a printed decision aid.

Decision aids are becoming increasingly common in a range of diverse conditions and clinical settings because they can reduce decisional conflict, improve patientclinician communication, improve the alignment of values and choice, and reduce the use of low value interventions [7]. The time-sensitive nature and frequently the suboptimal conduct of decision-making in the ICU highlight the necessity of tools to improve the efficiency and quality of the shared decision-making process $[2,6,17]$. Web-based or electronic decision aids have the potential to improve the cost of disseminating these tools and improve their efficacy by allowing customization of content or prognostic information based on patient's medical, demographic, educational, cultural, or religious characteristics.

eCODES is one of the first decision aids specifically directed towards surrogate decision makers of ICU patients. This role has been associated with significant conflict and personal distress, including a high incidence of PTSD-like symptoms [18]. eCODES incorporates many of the evidence-based principles to improve the quality of shared decision making and communication that may mitigate this impact for surrogate decision makers in the ICU namely, provision of clear information, assistance with 
Table 1 Usability attributes of eCODES by age group

\begin{tabular}{|c|c|c|c|c|c|}
\hline & $\leq 45 n=12$ & 46 to $55 n=7$ & 56 to $65 n=6$ & $\geq 66 n=5$ & Total $n=30$ \\
\hline \multicolumn{6}{|l|}{ Selected Systems Usability Scale total scores } \\
\hline Mean (SD) & $84(9)$ & $85(11)$ & $75(7)$ & $68(8)$ & $80(10)$ \\
\hline Median (IQR) & $83(80,88)$ & $95(80,95)$ & $74(70,78)$ & $68(60,75)$ & $80(73,88)$ \\
\hline Range & 70 to 95 & 68 to 95 & 70 to 88 & 60 to 75 & 55 to 95 \\
\hline \multicolumn{6}{|l|}{ Systems Usability Scale items* } \\
\hline $\begin{array}{l}\text { I think that I would like to use this program if } \\
\text { I had a loved one in the ICU }\end{array}$ & $11(92 \%)$ & $7(100 \%)$ & $5(83 \%)$ & $5(100 \%)$ & $28(93 \%)$ \\
\hline I thought the program was too complex & $0(0 \%)$ & $0(0 \%)$ & $0(0 \%)$ & $0(0 \%)$ & $0(0 \%)$ \\
\hline I thought the program was easy to use & $11(92 \%)$ & $7(100 \%)$ & $5(83 \%)$ & $4(80 \%)$ & $27(90 \%)$ \\
\hline $\begin{array}{l}\text { I think that I would need the support of a technical } \\
\text { person to be able to use the program. }\end{array}$ & $0(0 \%)$ & $0(0 \%)$ & $0(0 \%)$ & $1(20 \%)$ & $1(3 \%)$ \\
\hline $\begin{array}{l}\text { I found the information and questions in the program } \\
\text { were well integrated }\end{array}$ & $10(\%)$ & $7(100 \%)$ & $6(100 \%)$ & $5(100 \%)$ & $28(93 \%)$ \\
\hline I thought there was too much inconsistency in the program. & $0(0 \%)$ & $0(0 \%)$ & $0(0 \%)$ & $1(20 \%)$ & $1(3 \%)$ \\
\hline $\begin{array}{l}\text { I would imagine that most people would learn to use } \\
\text { this program very quickly }\end{array}$ & $12(100 \%)$ & $7(100 \%)$ & $6(100 \%)$ & $5(100 \%)$ & $29(97 \%)$ \\
\hline I found the program very cumbersome to use. & $0(0 \%)$ & $0(0 \%)$ & $0(0 \%)$ & $0(0 \%)$ & $0(0 \%)$ \\
\hline I felt very confident using the program & $11(92 \%)$ & $7(100 \%)$ & $6(100 \%)$ & $4(80 \%)$ & $28(93 \%)$ \\
\hline $\begin{array}{l}\text { I needed to learn a lot of things before I could get } \\
\text { going with this program. }\end{array}$ & $0(0 \%)$ & $0(0 \%)$ & $0(0 \%)$ & $0(0 \%)$ & $0(0 \%)$ \\
\hline \multicolumn{6}{|l|}{ I was able to:** } \\
\hline Answer the questions in the program & $12(100 \%)$ & $7(100 \%)$ & $6(100 \%)$ & $4(80 \%)$ & $29(97 \%)$ \\
\hline Complete the computer program & $12(100 \%)$ & $7(100 \%)$ & $6(100 \%)$ & $5(100 \%)$ & $30(100 \%)$ \\
\hline \multicolumn{6}{|l|}{ I was satisfied with:*** } \\
\hline The computer program overall & $12(100 \%)$ & 7 (100\%) & $5(83 \%)$ & $4(80 \%)$ & $28(93 \%)$ \\
\hline How easy it was to use the program & $12(100 \%)$ & 7 (100\%) & $6(100 \%)$ & $4(80 \%)$ & $29(97 \%)$ \\
\hline The layout of the program & $11(92 \%)$ & $7(100 \%)$ & $6(100 \%)$ & $4(80 \%)$ & $29(97 \%)$ \\
\hline The instructions & $12(100 \%)$ & $7(100 \%)$ & $6(100 \%)$ & $4(80 \%)$ & $29(97 \%)$ \\
\hline Prefer eCODES to printed version of decision aid & $11(92 \%)$ & $7(100 \%)$ & $6(100 \%)$ & $4(80 \%)$ & $29(97 \%)$ \\
\hline
\end{tabular}

${ }^{*} n(\%)$ who reported 'strongly agree' or 'agree'. ${ }^{* *} n(\%)$ who were able to perform the task. ${ }^{* * *} n(\%)$ who were 'very satisfied' or 'satisfied'.

eliciting and considering patient (as opposed to surrogate) values, and focusing on collaboration. Another valuable aspect of eCODES is its ability to export a printed distillation of the user's experience that can be used as a center point for a family-clinician meeting, thus emphasizing collaboration and information sharing.

The development of eCODES was motivated largely by family member feedback; the decision aid's high usability likely reflects their involvement in the iterative design process. As health care system participants increasingly trust and utilize digital health information, Web-based tools like eCODES will become increasingly common and used $[19,20]$. Electronic decision aids have the potential to integrate with electronic health records (EHRs), perhaps being prompted automatically in patient- and familyfacing portals when relevant clinical situations arise. The challenge will be to help patients and families interpret and personalize complex health information to best meet their needs and abilities. One relevant example in eCODES was the way we carefully constructed the presentation of individualized prognostic information to deliver this content in an easily understood and respectful manner. Because prolonged mechanical ventilation prognosis is often poor, our best efforts at presenting difficult information with tact, respect, and sensitivity may not be successful among all users - an area that requires further iterative revision.

This study also highlights the difficulty and resulting expense of developing a simple, usable decision aid for a complex use scenario that appeals to diverse groups of users. One can only imagine the resources needed to produce similar decision aids for all potential conditions. This reality highlights the need for a more comprehensive 'universal' approach to decision support that includes a common platform to standardize processes, a method for measuring and incorporating decisional outcomes feedback 
Table 2 Open ended written feedback for eCODES by age group

\begin{tabular}{|c|c|c|c|c|}
\hline & 45 and younger $n=12$ & 46 to $55 n=7$ & 56 to $65 n=6$ & 66 and older $n=5$ \\
\hline \multirow{12}{*}{$\begin{array}{l}\text { What did you like } \\
\text { most about the } \\
\text { eCODES program? }\end{array}$} & $\begin{array}{l}\text { - Easy information particularly if you } \\
\text { have no experience in this situation }\end{array}$ & & - iPad is a familiar platform & - Easy to use \\
\hline & - Easy to use & & - (it asked) good questions & - Informative \\
\hline & - It puts it in black and white & & - (helps) reinforce the decision & $\begin{array}{l}\text { - Information is easy to } \\
\text { use and helpful }\end{array}$ \\
\hline & $\begin{array}{l}\text { - It focuses the question at hand } \\
\text { on the patient }\end{array}$ & & - Wording is simple & - Gives another data point \\
\hline & - User friendly & & - Interactive & \\
\hline & - Self-explanatory & & & \\
\hline & $\begin{array}{l}\text { - How it broke the thought } \\
\text { process down }\end{array}$ & & & \\
\hline & $\begin{array}{l}\text { - [Gives] explanations for different } \\
\text { treatments }\end{array}$ & & & \\
\hline & $\begin{array}{l}\text { - I liked how patient and family } \\
\text { centered it was }\end{array}$ & & & \\
\hline & - Informative & & & \\
\hline & - It was interactive & & & \\
\hline & $\begin{array}{l}\text { - You could get good information } \\
\text { for your loved one }\end{array}$ & & & \\
\hline \multirow{3}{*}{$\begin{array}{l}\text { What did you dislike } \\
\text { most about the eCODES } \\
\text { program? }\end{array}$} & - A sensitive topic & & $\begin{array}{l}\text { - Doesn't make decision } \\
\text { for you }\end{array}$ & - Simplistic \\
\hline & - I don't like touch screens & & $\begin{array}{l}\text { - Back/forth buttons } \\
\text { have a delay }\end{array}$ & \\
\hline & & & $\begin{array}{l}\text { - I am an impatient person } \\
\text { with computers }\end{array}$ & \\
\hline \multirow{4}{*}{$\begin{array}{l}\text { How could the } \\
\text { eCODES program } \\
\text { be improved? }\end{array}$} & $\begin{array}{l}\text { - Would like even more information } \\
\text { about prognosis }\end{array}$ & & & $\begin{array}{l}\text { - Make [the information] } \\
\text { more complex }\end{array}$ \\
\hline & - Make forward button more obvious & & & \\
\hline & - Even more illustrations & & & \\
\hline & $\begin{array}{l}\text { - Make more options focusing on } \\
\text { each specific patient's case }\end{array}$ & & & \\
\hline
\end{tabular}

into decision making (e.g., electronic patient reported outcomes [PROs]), an approach to personalizing the patient/ user experience, and a learning health system-framed predictive analytics function informed by PRO and EHR system data [21-23]. While it may seem futuristic to those who are accustomed to the frustratingly fragmented clinical health informatics systems, it is telling that the electronic decision aid capability was anticipated and requested unprompted by our test users.

We recognize several important limitations. First, usability lacks a single accepted metric. We tried to address this by assessing multiple quantitative dimensions of usability and also eliciting open-ended feedback. Secondly, our sample size was relatively small and therefore may not reflect the values and experiences of all populations. We aimed to address this by purposefully sampling diverse age ranges, ethnicities, and ICU locations, though. Third, we found somewhat lower satisfaction and usability among those with older age - a group known to use mobile technology less frequently than younger groups [24]. While age-related disparities in adoption of mobile information technology will likely recede with time, we recognize that user interaction improvements could be important for the elderly. It is estimated that while $86 \%$ of adults have Internet access, many of lower socioeconomic status (a variable we did not measure) may have unique information technology needs [24]. Finally, we have described the development and user testing of eCODES in a hypothetical-use situation to attempt to focus users' attention on the decision aid and to control somewhat for patient-, personal-, and clinician-related effects that could cloud objectivity in a real-world scenario. The clinical efficacy, if any, of eCODES is being evaluated in an ongoing clinical trial.

\section{Conclusions}

We developed eCODES, a highly usable Web-based decision aid for surrogate decision makers of patients receiving 
prolonged mechanical ventilation, and then successfully implemented it in a clinical trial setting. Our experience shows that families of the critically ill desire electronic decision support and greatly prefer an electronic format to a printed alternative - even among the elderly who rated usability somewhat lower than younger participants. Electronic decision aids have great potential to contribute to more patient centered and family-orientated health care delivery in the very near future.

\section{Additional files}

Additional file 1: Figure S1. Evolution of eCODES development. eCODES represents the third in a series of decision aid versions dating to 2010. Important failures and detours are shown that are noted here: Version 1 (app): we explored the expansion of decision aid $\mathrm{v} 1$ to a tablet computer/ smartphone app, using its code as the foundation for programming. The app was successfully designed, but the development team dissolved at the end of the project leading to instability in app support and server maintenance, requiring us to abandon this angle. Another important limitation was that data could be transmitted from app to the server only, not from the server to the app. Version 2: However, we ultimately ended this partnership due to our concerns about the ability of the consultants to provide timely support and maintenance as well as a change in university regulation of electronic health data that prevented our use of a non-university server

Additional file 2: Security standards of study data system used to present eCODES.

\section{Additional file 3: Instructions for usability testing.}

Additional file 4: Figure S2. Screenshots from eCODES compared to the original written decision aid. These are selected screenshots from the third and final version of the decision aid (eCODES) that are contrasted to the original material from the written decision aid.

\section{Abbreviations}

eCODES: electronic Collaborative Decision Support; EHR: electronic health records; ICU: intensive care unit; ePRO/PRO: (Electronic) Patient-reported outcomes; ProVent: prolonged mechanical ventilation prediction model.

\section{Competing interests}

The authors declare that they have no competing interests. CC, DJ, BW, DW, JK, CH, and SC were supported by NIH grant R01 HL109823.

\section{Authors' contributions}

$C C, M T, B C, D J, N W$, and $C L$ contributed to the study design and concept. CC, NW, JK, CL, DW, CH, SC, DJ, BW, MT, BC, and MJ contributed to the writing and review. CC, BW, DJ, and NW contributed to the supervising of data collection. $\mathrm{BC}, \mathrm{MT}$, and $\mathrm{MJ}$ contributed to the programming and Web design. CC contributed to the acquisition of funding. CC, NW, DJ, BW, MT, BC, MJ, DW, CH, $\mathrm{JK}, \mathrm{SC}$, and $\mathrm{CL}$ contributed to the final approval. CC is accountable for all work. All authors read and approved the final manuscript.

\section{Acknowledgements}

Thank you to Siddharam Shingshetty, Manju lyer, Dean Chen, Joe Levy, and Mickey Mazarick for programming expertise and valuable suggestions.

\section{Author details}

'Department of Medicine, Division of Pulmonary and Critical Care Medicine, Duke University, Durham, NC 27710, USA. ${ }^{2}$ Program to Support People and Enhance Recovery, Duke University, Durham, NC, USA. ${ }^{3}$ Center for Learning Health Care, Duke Clinical Research Institute, Durham, NC, USA. ${ }^{4}$ Information Technologist, Sheps Center for Health Services Research, University of North Carolina at Chapel Hill, Chapel Hill, NC, USA. Information Technologist, Lineberger Comprehensive Cancer Center, University of North Carolina at Chapel Hill, Chapel Hill, NC, USA. ${ }^{6}$ Department of Critical Care Medicine, University of Pittsburgh School of Medicine, Pittsburgh, PA, USA.
7Department of Medicine, Division of Pulmonary and Critical Care Medicine, University of Washington, Seattle, WA, USA. ${ }^{8}$ Department of Medicine, Division of General Internal Medicine, University of Colorado, Denver, CO, USA. ${ }^{9}$ Department of Medicine, Division of Pulmonary and Critical Care Medicine, University of North Carolina at Chapel Hill, Chapel Hill, NC, USA.

Received: 11 December 2014 Accepted: 19 February 2015

Published online: 25 March 2015

\section{References}

1. Cox CE, Martinu T, Sathy SJ, Clay AS, Chia J, Gray AL, et al. Expectations and outcomes of prolonged mechanical ventilation. Crit Care Med. 2009;37:2888-94.

2. White DB, Braddock CH, Bereknyei S, Curtis JR. Toward shared decision making at the end of life in intensive care units: opportunities for improvement. Arch Intern Med. 2007;167:461-7.

3. Barry MJ, Edgman-Levitan S. Shared decision making - pinnacle of patient-centered care. N Engl J Med. 2012;366:780-1.

4. Sprung CL, Truog RD, Curtis JR, Joynt GM, Baras M, Michalsen A, et al. Seeking worldwide professional consensus on the principles of end-of-life care for the critically ill: the consensus for worldwide end-of-life practice for patients in intensive Care Units (WELPICUS) study. Am J Respir Crit Care Med. 2014;190:855-66.

5. Truog RD, Campbell ML, Curtis JR, Haas CE, Luce JM, Rubenfeld GD, et al. Recommendations for end-of-life care in the intensive care unit: a consensus statement by the American College of critical care medicine. Crit Care Med. 2008;36:953-63.

6. Uy J, White DB, Mohan D, Arnold RM, Barnato AE. Physicians' decision-making roles for an acutely unstable critically and terminally ill patient. Crit Care Med. 2013:41:1511-7.

7. Stacey D, Legare F, Col NF, Bennett CL, Barry MJ, Eden KB, et al. Decision aids for people facing health treatment or screening decisions. Cochrane Database Syst Rev. 2014;1, CD001431.

8. Cox CE, Lewis $C L$, Hanson LC, Hough CL, Kahn JM, White DB, et al. Development and pilot testing of a decision aid for surrogates of patients with prolonged mechanical ventilation. Crit Care Med. 2012;40:2327-34.

9. Elwyn G, O'Connor A, Stacey D, Volk R, Edwards A, Coulter A, et al. Developing a quality criteria framework for patient decision aids: online international Delphi consensus process. BMJ. 2006;333:417.

10. Carson SS, Garrett J, Hanson LC, Lanier J, Govert J, Brake MC, et al. A prognostic model for one-year mortality in patients requiring prolonged mechanical ventilation. Crit Care Med. 2008;36:2061-9.

11. Research-based web design \& usability guidelines. Accessed November 1 , 2013. Available at: http://www.usability.gov/sites/default/files/documents/ guidelines_book.pdf?post=yes.

12. Brooke J. A quick and dirty usability scale. In: Jordan PW, Thomas B, Weerdmeester BA, McClelland AL, editors. Usability evaluation in industry. London: Taylor and Francis; 1986.

13. Bangor A, Kotum P, Miller J. Determining what individual SUS scores mean adding an adjective rating scale. J Usability Stud. 2009:4:114-23.

14. Nielsen J. Usability 101: introduction to usability. Accessed March 28, 2014. Available at: http://www.nngroup.com/articles/usability-101-introduction-tousability/

15. Brooke J. System Usability Scale (SUS): a retrospective. J Usability Stud. 2013;8:29-40.

16. Cox CE. Improving decision making in patients with prolonged mechanical ventilation. Accessed February 1, 2015. Available at: http://clinicaltrials.gov/ show/NCT01751061

17. Butler M, Ratner E, McCreedy E, Shippee N, Kane RL. Decision aids for advance care planning: an overview of the state of the science. Ann Intern Med. 2014;161:408-18.

18. Lautrette A, Darmon M, Megarbane B, Joly LM, Chevret S, Adrie C, et al. A communication strategy and brochure for relatives of patients dying in the ICU. N Engl J Med. 2007;356:469-78.

19. Topol EJ. The creative destruction of medicine how the digital revolution will create better health care. New York: Basic Books; 2012.

20. Hesse BW, Nelson DE, Kreps GL, Croyle RT, Arora NK, Rimer BK, et al. Trust and sources of health information: the impact of the Internet and its implications for health care providers: findings from the first health information national trends survey. Arch Intern Med. 2005;165:2618-24. 
21. Cox CE, White DB, Abernethy AP. A universal decision support system. Addressing the decision-making needs of patients, families, and clinicians in the setting of critical illness. Am J Respir Crit Care Med. 2014;190:366-73.

22. Wysham NG, Abernethy AP, Cox CE. Setting the vision: applied patient-reported outcomes and smart, connected digital healthcare systems to improve patient-centered outcomes prediction in critical illness. Curr Opin Crit Care. 2014;20:566-72.

23. Institute of Medicine. In: Grossmann C, Powers B, McGinnis JM, editors. Digital infrastructure for the learning health system: the foundation for continuous improvement in health and health care - workshop series summary. Washington (DC): National Academies Press; 2011. Available at: http://www. ncbi.nlm.nih.gov/books/NBK83569/pdf/TOC.pdf. Accessed December 12, 2014

24. Pew Research Center. Pew research internet project. Accessed October 1, 2014. Available at: http://www.pewinternet.org.

\section{Submit your manuscript to a SpringerOpen ${ }^{\circ}$ journal and benefit from:}

- Convenient online submission

- Rigorous peer review

- Immediate publication on acceptance

- Open access: articles freely available online

- High visibility within the field

- Retaining the copyright to your article

Submit your next manuscript at $\gg$ springeropen.com 